ISSN-2199-353X

Online only at http://www.cahij.com/

\title{
SLAVLARIN GÜNEY KAFKASYA BASKINLARI
}

Oghuz Mammadli *

\begin{abstract}
Özet
$\mathrm{Bu}$ çalışmada, Arap Hilafeti'nin zayıflaması ve dağılmas sürecinde Güney Kafkasya'nın Hazar kıyıları bölgelerinin IX. Yüzyılda günümüz Ukrayna sınırları içinde Norman tayfalarından biri olan Ruslar tarafından kurulmuş Kiev Rus Devleti'nin yağma maksadıyla yaptığı seferleri ele alacağız. İlki 909 yılından başlayan seferlerin XI.yüzyıla kadar aralıksız devam etmesinden bahs edeceği. Ruslar ve sağalmaz yaralar vurnasından bahs edeceğiz. XVII yüzyılda Stepan Razin'in önderliğinde Hazar kıyılarına, aynı zamanda, Bakü’ye saldırısını ele alacağız.

Anahtar Kelimeler: Kafkasya, Hazar Denizi, Kiev Rus, Azerbaycan.
\end{abstract}

\section{THE RAIDS OF THE SLAVS ON THE SOUTH CAUCASIA}

\begin{abstract}
In this study, it is studied the campaigns of Kiev Russian State, one of Norman Crews in the nineth century, with the purpose of pillage the Hazar Front in the South Caucasia after dismemberment of Arabic Khilafat. The first campaign began in 909 and went on till eleventh century continuously. Also, Russians and wreckage by them and campaigns on Bakü and Hazar Fronts under the leadership of Stepan Razin in XVII century.
\end{abstract}

Key words: Caucasia, Hazar Sea, Kiev Russian, Azerbaijan.

\section{Giriș}

Merkezi Arap Hilafeti'nin zayıflayarak dağılma sürecine girmesi ile birlikte Hilafet topraklarında çeşitli yerel devletler yaranmaya başladı. Arap işgaline karşı en büyük mücadele vermiş Hürremilik harekatının merkezi olan Azerbaycan'da IX. Yüzyıldan itibaren devletler oluşmaya başlamıştır. Bu devletlerin bir kısmı Sacoğulları ve Salaroğulları gibi tüm Azerbaycan coğrafyası kapsamasıyla birlikte, coğrafyanın belirli kısmını kapsayan Şirvanşahlar, Şeddadiler ve Revvadiler devletleri oluşmuşdu. IX yüzyılda Kiev Rus Devleti'ni kurmuş Norman asıllı Ruslar deniz ve nehir yolları vasıtasıyla batıda Bizans, doğuda ise Hazar Kağanlığı vasıtasıyla bir çok devletler ile ticaret ilişkileri kurmuşlardı. Abbasi Hilafeti ile ticaret yapan Ruslar Don ve İdil nehirleri vasitasiyla Hazar Denizi'ne gelerek, buradan da kara yolu ile kervanlar vasıtasıyla Bağdad ile ticaret yapıyorlardı. Kendi ülkelerinden getirdikleri kürk, mum, bal getirerek karşılığında buradan ipek, yün, pamuk parçalar, düyü ve demir aletleri ile değiştiriyorlardı.

Ticaret yaptıkları ülkelere daha sonra yağma amacıyla baskın yapan Ruslar, aynı yolu kara yolları vasıtasıyla Bağdad ile ticaret yaptıkları Azerbaycan'a da baskınlar düzenlemişdir. XI. yüzyıldan itibaren Kiev Rus Devleti'nin zayıflaması, daha sonra Türk akınları karşısında yenilen Ruslar yalnız XVI.yüzyıldan itibaren yeniden Azerbaycan ile ticaret ilişkiler kurmaya başlamış, XVII. yüzyılın ortalarında ise asıl maksadını göstererek daha önceleri yaptıkları baskınları yeniden hayata geçirmişdir.

$\mathrm{Bu}$ çalışmada, Rusların X.yüzyıldan XI. yüzyıla kadar yaptıkları baskınları, devrin en büyük şehirlerinden olan Berde şehrini nasıl yok ettiklerini ele alacağız.

\footnotetext{
* Niğde Ömer Halisdemir Üniversitesi, Sosyal Bilimer Enstitüsü, Avrasya Araştırmaları Anabilim Dalı Doktora Ögrencisi, oghuzmammadli@gmail.com
} 
ISSN-2199-353X

Online only at http://www.cahij.com/

\section{Berde Faciası'na kadarki Rus baskınları}

Don-İdil-Hazar vasıtasıyla ticaret yapan Ruslar daha önceler de küçük çaplı baskınlar yapsa bile ilk defa düzenli ordular halinde 909 yılında 16 gemi ile Hazar Denizi'ne gelen Ruslar, güneydeki Abaskun adasını ele geçirerek sahil mıntıkarını yağmalamaya başladılar. Ardından Mekale isimli yere gelmiş Ruslar'a karşı yerli ahali büyük direnç gösterdiler. Gece Ruslar'ın üzerine hücum eden yerli ahali bir kısmını öldürdü, sağ kalanları ise Taberistan'a esir olarak götürdüler (Şerifli, 1978: 136).

Bir yıl sonra 910 yılında yeni baskına gelen Ruslar Sarı ve Penchezarın adasında ve sahil mıntıkalarında yangınlar, talanlar yaptılar. Ele geçirdikleri esir ve ganimetler ile Hazarın güneyine doğru hareket eden Ruslar'ın bir kısmı Deyleman'da bulunan Çeşmerud yakınlarına gittiler. Gemilerle gelmiş Ruslar'ın bir kısmı karada kamp kurdular, bir kısmıysa gemilerde kaldılar. Karada bulunan Ruslar'a karşı harekete geçen Gilanşah onları mağlup etti. Gemiler ile Kiev'e dönmek isteyen Ruslardan haber tutan Şirvanşah ise onları denizde kuşatarak hiç birini sağ bırakmadı (Eliyarlı ve diğerleri, 1996: 211).

Hazar Denizi'ni kullandıkları için Rus tacirleri Hazar Kağanlığı'na “onda bir” vergi veriyorlardı. Böylelikle denizi kullanarak ticaret yapıyorlardı. 910 yılındaki ağır mağlubiyetten sonra Ruslar 914 yılında her birinde 100 asker olan 500 gemi ile yeniden Hazar Denizine dahil oldular. Hazar Kağanlığ topraklarından geçtikleri için Ruslar elde edecekleri ganimetin yarısını Hazar Kağanı'na verecekleri taahhütü ile yeniden Azerbaycan'a saldırmaya başladılar. Ruslar 50000 kişilik ordu ile Pirallahı, Sahilan, Zire, Kiçik Zire, Büyük Zire, Zenbile, Xire, Sarı adalarında kamp kurarak Abşeron, Taberistan, Deylem ve Gilan bölgelerini talan etmeye başladılar (Aliyev, 2009: 232).

914 yılında yaşanmış olaylarla ilgili olarak Mesudi şöyle yazıyordu: "Ruslar çeşitli kollara ayrılan bir tayfadır. Onların en büyük kabilesi Urmandır. Onlar Endelüs, Roma, Konstatinopol ve Hazarlar ile ticaret yapıyorlar" (Şerifli, 1978: 137-138).

$\mathrm{Bu}$ sefer sonucunda çok sayıda ganimet elde etdiler. Geri dönerken Ruslar, söz verdikleri gibi ganimetin yarısını Hazar Kağanı'na gönderdiler. Fakat burada Hazar Kağanlığı'nda Müslüman-Türk ahalisi kendi din ve soydaşlarına yapılanları görüp Hazar Kağan'ından Ruslara karşı savaşmak için izin istediler. Bununla ilgili Mesudi şöyle yazıyor: "İzin ver, bunlarla hesaplaşalım. Onlar bizim müslüman kardeşlerimizin topraklarına baskın etdiler, onların kanını döküp, kadın ve çoçukları esir etdiler”. 15000 kişilik Harezm, Hazar, Burtas ve Bulgar Türklerinden oluşan Müslümanlar 3 gün Ruslarla savaşarak onları mağlup etdiler. Ruslardan sadece 5000 civarında olan bir kısım kaçarak sağ kalmayı başardılar. Bu ağır mağlubiyetten sonra Ruslar 30 yıl bir daha Azerbaycan'a gelmediler (Nuriyeva,2015: 66).

\section{Ruslar'ın Berde faciası ve kirahk askerliği}

Müslüman Türk orduları tarafından mağlup edilen Ruslar 30 y1llı bir aralıktan sonra yeniden Hazar Denizi kıyılarında görülmeye başlandı. 941 yılında Kiev Knezi İgor kendisine bağlı ve kiralık askerlerden oluşan büyük bir ordu ile Bizans'a sefere hazırlanıyordu. Tüm hazırlıklar tamamlandığı zaman Bizans ile barış antlaşması imzalandı. Böylece İgor'a bağlı ve paralı olan askerler işsiz kaldılar. Bu zaman İgor Peçenekler'den ibaret kara kuvvetlerinin bir kısmını Dunay tarafa göndermiş, donanmasını ise Hazar vilayetlerine göndermiş. Lakin bu seferde İgor'un kendisi komutanlık yapmıyordu (Bartold, 1963 : 690). Ruslar'ın 944 yılında yaptıkları önceki seferlerinden çok daha farklıydı. Nitekim, Ruslar'ın bu defaki hedefleri Yakın ve Orta Doğu'nun en büyük, zengin, ticaret ve sanatçılık merkezlerinden biri olan Berde şehri idi. X. Yüzyıl Arap yazarları Azerbaycan şehirlerinden bahs ederken Berde şehri önemle vurguluyorlardı. İstahri Berde hakkında şöyle yazmışdır: "Irak'ta ve Horasan'da Rey'den ve İsfahan'dan sonra Berde kadar büyük, gelişen ve güzel şehir yoktur”. İbn Havkal ise Berde'de ipekten çeşitli mahsüller hazırlandığını ve mahsüllerin yurtdışına satıldığından bahs ediyor (Abdullayev ve diğerleri, 2014: 78).

Kiev Knezi İgor'un kendisine bağlı ve kiralık askerden oluşan kalabalık ordusu Rus müsteşriki Yakubovski'nin deyimi ile "Kafkasya'nın en büyük şehri”ni işgal etmek için Hazar Denizine dahil oldular (Şerifli, 1978: 144). Kür nehrinin Hazar denizine döküldüğü yerden nehre dahil olan Ruslar gemilerle batıya doğru hareket ederek, Berde yakınlığındaki Mübareki isimli yerde kamp kurdular (Eliyarlı ve diğerleri, 1996: 212). Gemilerin korunması amacıyla 300 kişilik ordu bırakan Ruslar Berde şehrine doğru hareket ettiler. Devrin Salari Devleti’nin parçası olan Berde şehrinde takriben 5000-6000 
ISSN-2199-353X

Online only at http://www.cahij.com/

civarında asker vardı. Ruslar'ın sayı ise 10 kat fazlaydı. Ruslar'a fazla direnç göstere bilmeyen Berde şehri Ruslar tarından işgal edildi. İbn Miskeveyh bu olay ile ilgili şöyle yazıyordu: "O yıl Azerbaycan'a Er-Rus ismi ile meşhur olan kavmin ordusu geldi, onlar Berde'ye hareket ederek o şehri işgal ederek, ahalisini esir aldılar'. Ruslar'ın Berde'yi işgal etmesinden haber veren İbn Miskeveyh Ruslar'ın kendileri hakkında da bilgi vermişdir. İbn Miskeveyh yazıyordu: "Ruslar büyük vücudları ve cesaretleri farklanan bir halktır. Onlar savaştan kaçmanın ne olduğunu bilmiyorlar ve hiç biri arkasını (düşmana) çevirip kaçmıyorlar. Onların örfüne göre her biri silah taşımalı ve kendisi ile balta, testere, çekiç ve sanat aletleri taşımalıdırlar. Onlar savaş zamanı nize, kalkan ve kılıç kullanıyorlar. Hançere benzeyen silah taşıyan Ruslar, yaya olarak savaşıorlar (Dorn, 1875: 6).

Berde valisinin ordularını mağlub ederek şehri alan Ruslar şehir ahalisine "Bizim yüklülümügüuz size karşı iyi davranmak, sizin yükümlülügünüz ise bize itaat etmekdir. Şehir ahalisinin bir kısmı bu teklifleri kabul etse de, bir kısmı razılaşamayarak Ruslara baskınlar düzenliyorlar” (Şerifli, 1978: 149).

Şehirde kontrolu sağlamakta zorluk çeken Ruslar nihayetinde ahaliye 3 gün içinde şehri terk etmelerini talep ediyor. Binecek hayvanatı ve parası olan ahali şehri terk etti. Bu imkanları olmayarak şehirde kalan ahaliyi ise Ruslar "Şehristan" isimli içkaleye topladılar. Kendileri de bu içkalede kalan Ruslar 20 dirhem karşılığında insanların kendi canlarını satın almalarını teklif ettiler. Parası olan ahali canını satın alarak şehri terk etse de canını alamayan ahali Ruslar tarafından kılıçtan geçirildi. Kaynaklardaki malumatlara göre Berde'de yaklaşık 20000 kişi kılıçtan geçirildi (Eliyarlı ve diğerleri, 1996: 212).

Berde şehrinin bu zor zamanında Azerbaycan hükümdarı İbn Muhammed 30000 kişiden oluşan ordusuyla şehri kuşattı. Bir kaç sefer şehri geri almak istemesine rağmen başaramayan İbn Muhammed, Musul hakimi Ebu Muhammed Nasireddövle'nin ordularının Azerbaycan'ın Hoy ve Salmas şehrini işğal etmesi haberini alınca ordusundan 4000 civarında askeri Berde'nin kuşatmasında bırakarak güneye doğru hareket etmek mecburiyetinde kaldı. Vakit geçtikçe soğuk iklimden gelen Ruslar sıcak topraklarda hastalanmaya başladılar. Günbegün hastalıktan ölen Ruslar şehirde daha fazla tutunamayacaklarını anladılar. Kendileri ile götüremeyecekleri eşyaları yakan Ruslar elde ettikleri büyük ganimet ile geceleyin şehri terk etmeye başladılar. Daha önce gemilerini sakladıkları Mübareki mıntıkasına gelen Ruslar buradan Kür nehri vasıtasıyla Hazar Denizi'ne çıktılar. Hazar Denizi'ne çıkan Ruslar İdil-Don nehirlerinin vasıtasıyla Kiev'e geri dönmeyi başardılar. (Nuriyeva, 2015: 67)

İbn Muhammed'in ölmesi ile birlikte Salaroğulları arasında çıkan çatışmalar neticesinde merkezi devlet yıkıldı. Yıkılan devletin yerine Azerbaycan'ın belirli kısımlarını kendinde birleştiren devletler yaranmaya başladı. Ruslar'ın baskınları ise devam ediyordu. Ortak düşmana karşı birleşmek yerine maalesef yerli hakimler kendi aralarındaki anlaşılmazlıklar çözmek maksadıyla Ruslar'ın askeri güçlerinden yardım almaya başlamışlardı.

Azerbaycan'ın kuzey kapısı olan Derbent'in hakimi Maymun ibn Ahmet onu hakimiyetten salmaya çalışan yerli feodellere karşı Ruslar'dan yardım almışdı. 987 yılında 18 gemi ile Derbent'e hücuma hazırlaşan Ruslar'ı kiralık asker olarak Derbent'e davet etmiş ve bu vesile ile yerli feodelleri mağlup etmiş̧ti. Bundan sonraysa Rus askerlerinden oluşan özel kuvvet barındırdı (Eliyarlı ve diğerleri, 1996: 213).

Kür ve Araz nehirlerinin birleştiği yere 1030 yılında 38 gemi ile gelen Ruslar burada Şirvanşahlar'ın ordularını mağlub ettiler. Araz nehri ile ilerlemeye başlayan Ruslar'dan bu defa Şeddadi hükümdarı Fazl İbn Muhammed'in oğlu Musa Beylegan'da isyan çıkarmış kardeşi Eskuye'yi mağlup etmek için çoklu sayıda para verdi. Kardeşi Eskuye'yi Ruslar vasıtasıyla mağlup eden Musa onlara çok sayıda hediyeler verdi. Bu Ruslar ise kara yolu vasıtasıyla Bizans'a geçerek oradan kendi ülkelerine gittiler (Nuriyeva, 2015: 68).

Bu hadiseden 2 y1l geçdikten sonra Ruslar yeniden Azerbaycan'da gözüktüler. 1032-1033 yıllarında Ruslar Alanlar ve Serirler ile birlikte Şirvanşahlar devletine hücum ettiler. Devletin başkenti olan Yezidiye'yi (Şamahı) ele geçiren Ruslar, kaynakların verdiği bilgilere göre 10000'e kadar insanı kılıçtan geçirdiler. Kendi yurtlarının savunan yerli ahali Rus ve müttefiklerini ülkeden kovmayı başardı. Şirvan'1 yağmalayarak geri dönen Rus, Alan ve Serirler'i Derbent hakimi Mansur İbn Maymun ağır 
ISSN-2199-353X

Online only at http://www.cahij.com/

mağlup ederek ganimetlerine el koydu. Bir yıl sonra Mansur İbn Maymun'dan intikam almak maksadiyla Alanlar ve Ruslar Derbent'e saldırsalar bile mağlup olarak geri çekildiler (Eliyarlı ve diğerleri 1996: 213).

\section{Sonuç}

Azerbaycan'daki devletler arasındaki iç çatışmalar ve Ruslar'ın yağma maksadıyla aralıksız olarak yapmış hücumlar sonucunda ahali ekonomik, insani ve kültürel açıdan büyük darbe aldı. Kuzey'de kurulmuş Kiev Rus Knezliği gittikçe güçlenerek komşu devletlere de saldırmaya başladılar. 965 senesinde Svyatoslav İdil etrafı ve Kuzey Kafkasya'ya yapmış olduğu yürüş sonucunda Hazar Kağanlığı bir devlet olarak siyasal önemini kayb etti. Kafkasya'nın kuzey-batısında Tmurtakan devleti yaranarak bölge için bilhassa Bizans için büyük tehdit haline geldi. Yalnızca Kıpçaklar'ın XI.yüzyılın ortalarında Kuzey Kafkasya'ya yürüyüşleri sonucunda bu devlet ortadan kalktı. Kıpçaklar'ın tesiri sonucundan Kiev Rus Devlet'i istediği gibi hareket edemez hale gelmiş oldu. Ruslar'ın Bizans ile savaşından bahs eden XII.yüzyıl Farsdilli Azerbaycan edebiyatının şairlerinden Nizami Gencevi şöyle yazmıştır:

Ruslar her tarafta gösterir hiddet,

Rumların başına açır giyamet.

Sohulmuş Rum ile Rus biribirine

Benzer ağ, gırmızı donlu geline (Gencevi, 2004: 366).

Azerbaycan'a yapılan yürüyüşler sonucunda "Kafkasya'nın en büyük şehri” olan Berde şehri bir daha eski günlerine kavuşamadı. Güney'de savaşlarla meşgul olan Salaroğulları Berde'ye önem vermediler. Bundan dolayıdır ki, kuzey-batı'da Şeddadoğulları tarafından kurulmuş devletin başkenti Berde değil Gence olarak seçildi. Berde'de Ruslar'ın yaptıkları korkunç ve zalimce olduğundan dolayı Nizami Gencevi şöyle yazmıştır:

İndi o dergahın tahtı alçalmış,

İpeyi, kumaşı külekler sarmış.

Taze nar gülleri dökülüp solmuş,

O narlar, nergizler dönüb toz olmuş.

İndi ise yerinde bu güzel yurdun,

Var sel yumuş dere, kurumuş odun.

Yine de bol olan göyertiler,

Adalet tohumundan göyerse eğer (Gencevi, 2004: 208).

Devrin devletler ve halklar arasında olan ilişkilerini anlamak açısından Nizami Gencevinin aşağıdaki şiiri çok manidardır:

Hazar dağından Çin suyuna kadar

Türklerle doludur bütün bu yerler.

Bilirem Rumlar'1 sevmeyir bir Türk,

Rumlar'a kinleri Rus'tan da büyük.

Türkler'in oku ile yine bu zaman

Gabar eksik olmaz Rus ayağından (Gencevi, 2004: 333)

Azerbaycan'ın tek vücud halinde olmamasını iyi kullanan Ruslar'ın bu yürüşleri Selçuklu Devleti'nin kurulması ile sona ermiştir. Tarihin sonraki dönemlerinde iç kargaşa ve Altınordu Devleti'nin bir vilayeti olduğu dönemlerde güneye dönemeyen Ruslar yalnızca, yalnızca XVII.yüzyılın sonlarından itibaren yeniden güneye doğru çevrilmeye başlamıştır.

\section{KAYNAKÇA}

Şerifli, Memmedali (1978), “IX.asrın ikinci yarısı - XI.asrlarda Azerbaycan Feodal Devletleri”, Bakü. 
ISSN-2199-353X

Online only at http://www.cahij.com/

Eliyarlı Süleyman, Mahmudov Ferman, Babayev İlyas, Mahmudov Yaqub, Onullahi Seyidağa, Şükürlü Kerim, Abdulla Mehman, Tağıade Şövket, Muhtar oğlu Vilayet (1996), “Azerbaycan Tarihi”, Bakü.

Aliyev, Gabil (2009), "Kafkas Tarihi”, Bakü.

Nuriyeva, İrade (2015), “Azerbaycan Tarihi”, Bakü.

Bartold, Vasiliy (1963), "Sochineniya, Tom II, cast 1", Moskva.

Abdullayev Mehman, Eliyarlı Süleyman, Süleymanova Sevda, Memmedov Hakani, Bayramov Zabil, Babayeva Tamilla, Nesibov Yunis, Şabiyev Beymirze, Mehdiyev Erestun, Hüseynli Resul, Memmedov Kerem, Aliyeva Lale, Süleymanlı Rabil, Şirinova Emine, Cavanşir Nurlana, Hasanov Erşad, İbrahimova Ülviyye, Cavadova Almas, Memmedova Arzu (2014), “Azerbaycan Tarihi”, Bakü.

Gencevi, Nizami (2004), “İskendername”, Bakü.

Dorn, Boris (1875), "Kaspiy”, St.Petersburg. 